3. Li J., Zhang Y., Hu D.-M. và cộng sự. (2020). Impact of postoperative complications on longterm outcomes of patients following surgery for gastric cancer: A systematic review and metaanalysis of 64 follow-up studies. Asian J Surg, 43(7), 719-729.

4. Serra M.A.A. de O., Filho F.F. da S.,
Albuquerque A. de O. và cộng sự. (2015) Nursing care in the immediate postoperative period: a cross-sectional study. Online Braz J Nurs, 14(2), 161-7.

5. Qi S. và Yuanyuan W. (2019). Effect of systemic nursing on postoperative recovery of gastric cancer patients. Int J Curr Res, 11(11), 8179-8181.

\title{
KIẾN THỨC CỦA NGƯờI NHIỄM HIV/AIDS VÊ TRÂM CẢM TẠI 2 PHÒNG KHÁM NGOẠI TRÚ TỈNH THÁI BÌNH
}

\section{TÓM TẮT}

Mục tiêu: Đánh giá kiến thức của người nhiễm HIV/AIDS về trâm cảm tại 2 phòng khám ngoại trú tỉnh Thái Bình năm 2019. Đối tượng nghiên cứu: bệnh nhân HIV/AIDS người lớn $\geq 18$ tuổi đang điều trị ARV. Phương pháp nghiên cứu: Phương pháp mô tả thông qua cuộc điều tra cắt ngang. Kết quả nghiên cứu: Tỷ lệ đối tượng nghiên cứu đã từng được nghe ít nhất 1 lần về bệnh trầm cảm chiếm tỷ lể khá cao $(92,8 \%) ; 36,5 \%$ số đối tượng nghiên cứu biết được từ 4/6 biểu hiện của cả 2 giai đoạn khởi phát và toàn phát của bệnh; Chỉ có $31,6 \%$ người bệnh kể được 2-3 trong số 3 nhóm nguyên nhân chính; Tỷ lệ đối tượng nghiên cứu có kiến thức đạt về trầm cảm chiếm tỷ lệ 69,7\% Bình.

Tư khóa: Kiến thức về trâm cảm; HIV/AIDS; Thái

\section{SUMMARY \\ KNOWLEDGE OF HIV/AIDS PATIENTS \\ ABOUT DEPRESSION AT 2 OUTPATIENT \\ CLINICS IN THAI BINH PROVINCE}

Objectives: Describe the knowledge of HIV/AIDS patients about depression at 2 outpatient clinics in Thai Binh province in 2019. Subjects: HIV / AIDS patients adults $\geq 18$ years old being treated with ARV. Method: Descriptive method through cross-sectional survey. Results: The percentage of study subjects who have heard at least 1 time about depression is quite high (92.8\%); And a low rate $(36.5 \%)$ of the study population knew from 4 out of 6 signs of the stages of the disease; Only $31.6 \%$ of patients known 2-3 of the 3 main causes of the depression; The percentage of study subjects with knowledge about depression was $69.7 \%$.

Keywords: Knowledge about depression; HIV/AIDS; Thai Binh

\footnotetext{
${ }^{1}$ Trường Đại học Y Dược Thái Bình

${ }^{2}$ Bênh viênn Bach Mai

Chịu trách nhiệm chính: Ngô Văn Mạnh

Email: manhsdh@gmail.com

Ngày nhận bài: 9.9.2021

Ngày phản biên khoa hoc: 29.10.2021

Ngày duyệt bài: 11.11.2021
}

Ngô Văn Mạnh ${ }^{1}$, Lê Đức Cường ${ }^{1}$, Bùi Thị Huyền Diệu ${ }^{1}$, Vũ Thị Quỳnh Trang ${ }^{2}$

\section{I. Đă̆T VẤN ĐỀ}

Hơn 30 năm qua, kể từ khi phát hiện ra HIV cho đên nay, cộng đồng quốc tế đã nỗ lực rất lớn trong công tác chăm sóc, điều trị HIV/AIDS nhằm đẩy lùi sự gia tăng của đại dịch AIDS và đã thu đước nhiêu kết quả đáng ghi nhân đó là sư phát triển tổng thể của dich AIDS toàn cầu có vẻ như đã ổn định. Số người nhiễm mới HIV hàng năm giảm xuống đáng kể từ cuối những năm 1990 và tử vong liên quan AIDS ít dân do việc mở rộng điều trị kháng HIV[1].

Cùng với nỗ lực điều trị HIV, ngoài việc người bệnh được hỗ trợ nhằm tăng cường sức khỏe thể chất thì sức khỏe tâm thần của người nhiễm HIV cũng là một trong những vấn đề cần được quan tâm. Người bệnh có thể gặp phải các vấn đề sức khỏe tầm thần bắt đầu từ rất sớm ngay khi có chẩn đoán ban đầu và có thể phát sinh trong cả thời gian điều trị bệnh. Các vấn đề phổ biến thường gặp phải là trầm cảm, lo âu và làm dụng các chất gây nghiện. Trong đó, trầm cảm là biên chứng thần kinh phổ biến nhất ở bênh nhân nhiếm HIV và hạn chế đáng kể chất lượng cuộc sống của bệnh nhîan HIV/AIDS [2].

Các nghiên cứu trên thế giới cũng cho thấy việc điều trị những người bệnh trầm cảm cũng thực sự khó khăn nếu như họ không tự nhận thức được vấn đề họ gặp phải. Các nhà nghiền cứu đã chỉ ra rằng nhận thức thấp về bệnh không những liên quan đến việc bệnh nhân trầm cảm không đên cơ sở chăm sóc y tế cho đến khi bệnh kéo dài, trở nên trầm trọng hơn mà còn ảnh hưởng lớn đối với việc tìm kiếm sư giúp đõ và cam kết với những can thiệp được đề nghị và cả phòng ngừa [3], [4]. Vì vậy chúng tôi tiến hành nghiên cứu để tài với mục tiêu:

Tìm hiểu kiến thức của người nhiễm HIV/AIDS về träm cảm tại 2 phòng khám ngoại trú tỉnh Thái Binh năm 2020. 


\section{II. ĐỐI TƯỢNG VÀ PHƯƠNG PHÁP NGHIÊN CỨU} 2.1. Địa điểm, thời gian, đối tượng nghiên cứu

- Địa điểm nghiên cứu: 02 phòng khám ngoại trú gồm: Phòng khám ngoại trú Bệnh viện Đa khoa thành phố Thái Bình và Phòng khám ngoại trú Bệnh viện Đa khoa huyện Kiến Xương

- Đối tượng nghiên cứu: Là bệnh nhân HIV/AIDS người lớn $\geq 18$ tuổi (gọi tắt là người bệnh) đang điều trị ARV tại 2 phòng khám nghiên cứu.

- Thời gian nghiên cứu: Nghiên cứu được thực hiện từ 10/2019 - 5/2020

\subsection{Phương pháp nghiên cứu}

2.2.1. Thiết kế nghiên cứu. Nghiên cứu mô tả thông qua cuộc điều tra cắt ngang.

2.2.2. Cỡ mẫu và phương pháp chọn mẫu

a/ Cỡ mẫu: Toàn bộ bệnh nhân đang điều trị tại 2 phòng khám được lựa chọn vào nghiên cứu Tổng số điều tra 386 bệnh nhân.

b/ Phương pháp chọn mẫu: Tiến hành chọn chủ đích 02 phòng khám ngoại trú tại Bệnh viện Đa khoa Thành phố Thái Bình và Bệnh viện Đa khoa huyện Kiến Xương.

Tiến hành điều tra toàn bộ bệnh nhân điều trị tại 2 phòng khám đã chọn tại thời điểm nghiên cứu.

\subsection{Phương pháp thu thập thông tin}

Thông tin định lượng được thu thập thông qua: phiếu phỏng vấn trực tiếp người nhiễm HIV/AIDS đang điêuu trị ARV tại địa bàn nghiên cứu được chọn để đánh giá kiển thức của người bệnh về trầm cảm.

2.4. Các tiêu chuẩn sử dụng trong nghiên cứu

- Chúng tôi đánh giá dựa vào điểm trung bình kiến thức/điểm tối đa kiến thức đạt được của câu hỏi đó, hoặc tỷ lệ trả lời ý đúng của câu hỏi đó.

- Điểm trung bình kiến thức được tính: Tổng các ý trả lời đúng/Tổng số người được hỏi

- Kiến thức theo số điểm trả lời đúng: với trên $50 \%$ số điểm được cho là đạt yêu cầu. Tổng điểm kiến thức là 21 . Như vậy người bệnh được cho là đạt kiến thức là phải đạt ít nhất 11 điểm.

2.5. Xử lý số liệu. Số liệu sau khi điều tra được làm sạch thô và nhập vào máy vi tính bằng phần mềm EPI-DATA, sau đó chuyển sang phần mềm SPSS 20.0 để xử lý với các test thống kê y học.

\section{KẾT QUẢ NGHIÊN CỨU}

Bảng 3.1. Tỷ lệ người bệnh đã từng nghe nói về tràm cảm và nguốn thông tîn ( $n=$ 386)

\begin{tabular}{|c|c|c|}
\hline Thông tin & Số lượng & Tỷ lệ (\%) \\
\hline Đã nghe về trầm cảm & 358 & 92,8 \\
\hline
\end{tabular}

\begin{tabular}{|c|c|c|}
\hline $\begin{array}{c}\text { Chưa nghe về trầm } \\
\text { cảm }\end{array}$ & 28 & 7,2 \\
\hline \multicolumn{2}{|c|}{ Nguồn thông tin $(\mathrm{n}=358)$} \\
\hline Tivi, Internet.... & 311 & 86,9 \\
\hline Sách, báo, tạp chí... & 103 & 28,8 \\
\hline Nghe người khác nói & 121 & 33,8 \\
\hline
\end{tabular}

Qua bảng 3.1 cho thấy có 358 bệnh nhân chiếm 92,8\% ĐTNC đã được nghe nói hoặc xem, đọc thông tin về bệnh trầm cảm. Trong số đó phần lớn được biết đến thông tin về bệnh trầm cảm qua Tivi và mạng Internet chiếm $86,9 \%$, tiếp đó có $33,8 \%$ được nghe thông tin nhờ người khác nói và chỉ có $28,8 \%$ tiếp cận thông tin về trầm cảm qua sách, báo và các tạp chí.

Bảng 3.2. Tỷ lệ người bệnh có kiến thức về biếu hiện ban đầu của trâm cảm ( $n$ = 386)

\begin{tabular}{|c|c|c|}
\hline Biểu hiện ban đâu & \begin{tabular}{|c|c|} 
Số \\
lượng
\end{tabular} & $\begin{array}{l}\text { Tỷ lệ } \\
(\%)\end{array}$ \\
\hline $\begin{array}{l}\text { Mất ngủ, mệt mỏi, đau đầu } \\
\text { giống như suy nhược thần kinh }\end{array}$ & 176 & 45,6 \\
\hline $\begin{array}{l}\text { Mất khả năng làm việc, hay do } \\
\text { dự, không thiết tha thói quen, } \\
\text { sở thích cũ }\end{array}$ & 147 & 38,1 \\
\hline $\begin{array}{c}\text { Có ý tưởng, hành vi tự hủy hoại } \\
\text { bản thân }\end{array}$ & 132 & 34,2 \\
\hline Không biết & 114 & 29,5 \\
\hline
\end{tabular}

ĐTNC biết rằng biểu hiện ban đầu của trầm cảm là mất ngủ, mệt mỏi, đau đâuu giống như suy nhược thần kinh; $38,1 \%$ cho rằng trầm cảm ban đâu có mất khả năng làm việc, hay do dự, không thiết tha thói quen, sở thích cũ;; 34,2\% cho rằng người bệnh trầm cảm có ý tưởng, hành vi tự hủy hoại bản thân. Và có tới $29,5 \%$ người bệnh còn lại không biết 1 biểu hiện ban đầu nào của bệnh trầm cảm.

Bảng 3.3. Tỷ lệ người bệnh có kiên thức về biếu hiện khí phát bệnh của trầm cảm $(n=386)$

\begin{tabular}{|c|c|c|}
\hline Biểu hiện khi phát bệnh & $\begin{array}{c}\text { Số } \\
\text { Iượng }\end{array}$ & $\begin{array}{c}\text { Tỷ lệ } \\
\text { (\%) }\end{array}$ \\
\hline $\begin{array}{c}\text { Buồn râu, ủ rũ, mất hứng thú } \\
\text { với xung quanh. }\end{array}$ & 180 & 46,6 \\
\hline $\begin{array}{c}\text { Suy nghĩ chậm chạp, hoang } \\
\text { tưởng, mất niêm tin vào bản thân }\end{array}$ & 118 & 30,6 \\
\hline $\begin{array}{c}\text { İt hoạt đồng, ít nói, thường } \\
\text { nằm, ngồi yên một chô̂, măht } \\
\text { mày đau khổ, có thể kích động }\end{array}$ & 191 & 49,5 \\
\hline Khác & 01 & 0,3 \\
\hline Không biết & 129 & 33,4 \\
\hline
\end{tabular}

Trong số 386 người bệnh được phỏng vấn có 49,5\% người cho rằng khi phát bệnh người bệnh 
trầm cảm có biểu hiện: Ít hoat động, ít nói, thường nằm, ngồi yên một chố, mặt mày đau khổ, có thể kích động; Buồn rầu, ủ rũ், mất hứng thú với xung quanh chiếm 46,6\%; Suy nghĩ chậm chạp, hoang tưởng, mất niềm tin vào bản thẩn là $30,6 \%$. Có 01 người bệnh cho rằng giai đoạn toàn phát người bệnh trầm cảm có biểu hiện khác là muốn tự tử. Có 33,4\% người bệnh không biết giai đoạn toàn phát bệnh trầm cảm người bệnh có biểu hiện như thế nào.

Bảng 3.4. Tỷ lệ người bệnh biêt nguyên nhân của trâm cám $(n=386)$

\begin{tabular}{|c|c|c|}
\hline Nguyên nhân & $\begin{array}{c}\text { Số } \\
\text { lượng }\end{array}$ & $\begin{array}{c}\text { Tỷ lệ } \\
\text { (\%) }\end{array}$ \\
\hline $\begin{array}{c}\text { Do chấn thương tâm thần và } \\
\text { cơ thể. }\end{array}$ & 253 & 65,5 \\
\hline $\begin{array}{c}\text { Do dùng thuốc có tác dụng } \\
\text { phụ gây trầm cảm }\end{array}$ & 74 & 19,2 \\
\hline $\begin{array}{c}\text { Tự nhiên bị bệnh, không rõ } \\
\text { nguyên nhân }\end{array}$ & 134 & 34,7 \\
\hline Không biết & 80 & 20,7 \\
\hline
\end{tabular}

Phần lớn những người được hỏi biết rằng nguyên nhân gây ra trầm cảm là do chấn thương tâm thần và cơ thể $(65,5 \%) ; 34,7 \%$ biết rằng người bệnh trầm cảm tự nhiên bị bệnh, không rõ nguyên nhân là gì; có $19,2 \%$ biết trầm cảm có thể do dùng thuốc có tác dụng phụ gây trầm cảm. Có 20,7\% đối tượng không biết nguyên nhân của bệnh trầm cảm.

Bảng 3.5. Tỷ lệ người bệnh biêt hậu quả của trầm cảm $(n=386)$

\begin{tabular}{|c|c|c|}
\hline Hậu quả & $\begin{array}{c}\text { Số } \\
\text { lượng }\end{array}$ & $\begin{array}{c}\text { Tỷ lệ } \\
\text { (\%) }\end{array}$ \\
\hline Tử vong sớm do bệnh cơ thể & 34 & 8,8 \\
\hline $\begin{array}{c}\text { Làm hại bản thân và người } \\
\text { xung quanh }\end{array}$ & 253 & 65,5 \\
\hline Tự tử & 225 & 58,3 \\
\hline Không biết & 38 & 9,8 \\
\hline
\end{tabular}

Về hậu quả của bệnh trầm cảm: Làm hại bản thân và người xung quanh là hậu quả được nhiêu đối tượng nghiên cứu biết đến nhất chiếm $65,5 \%$, sau đó đến tự tử chiếm $58,8 \%$. Chỉ có $8,8 \%$ đối tượng nghiền cứu cho rằng trầm cảm có thể khiến người bệnh tử vong sớm do các bệnh cơ thể khác. Chỉ có 9,8\% ĐTNC không biết hậu quả của trầm cảm.

Bảng 3.6. Tỷ lệ người bệnh biêt phương pháp đîêu trị trầm cảm $(n=386)$

\begin{tabular}{|c|c|c|}
\hline Điêuu trị & $\begin{array}{c}\text { Số } \\
\text { lượng }\end{array}$ & $\begin{array}{c}\text { Tỷ leê } \\
\text { (\%) }\end{array}$ \\
\hline \multicolumn{2}{|c|}{ Cần thiết điều trị ( $\mathrm{n}=386)$} \\
\hline Cần được điều trị & 374 & 96,9 \\
\hline Không cần được điêu trị & 12 & 3,1 \\
\hline
\end{tabular}

\begin{tabular}{|c|c|c|}
\hline \multicolumn{3}{|c|}{ Phương pháp điều trị $(\mathrm{n}=374)$} \\
\hline Phấu thuật & 6 & 1,6 \\
\hline Uống thuốc & 214 & 55,4 \\
\hline Vật lý trị liệu & 118 & 30,6 \\
\hline Khác & 03 & 0,5 \\
\hline Không biết & 106 & 27,5 \\
\hline
\end{tabular}

Qua bảng 3.6 cho thấy hầu hết người bệnh được hỏi cho rằng bệnh trầm cảm cần được điều trị $(96,9 \%)$. Chỉ có $3,1 \%$ bệnh nhân cho rằng bềnh này không cần điều trị. Về phương pháp điều trị $55,4 \%$ bệnh nhân cho rằng bệnh trầm cảm có thể điều trị bằng uống thuốc, $30,6 \%$ cho rằng có thể điều trị trầm cảm bằng vật lý trị liệu, $1,6 \%$ cho rằng có thể phẫu thuật, $0,5 \%$ chọn điều trị bằng phương pháp khác là điều trị tâm lý. Có đến 27,5\% ĐTNC không biết phương pháp điều trị trầm cảm.

Bảng 3.7. Đánh giá kiến thức về trâm cám của người bệnh đang điều trị ARV (n = 386)

\begin{tabular}{|c|c|}
\hline Mức độ đánh giá & Giá trị \\
\hline Điếm thấp nhất & $02 / 21$ \\
\hline Điếm cao nhất & $20 / 21$ \\
\hline Điểm trung bình & $12,5 / 21$ \\
\hline Tỷ lệ có kiến thức đạt ( $\geq 11 / 21$ điểm) & $69,7 \%$ \\
\hline Tỷ lệ có kiến thức chưa đạt & $30,3 \%$ \\
( $\leq 10 / 21$ điểm) & \\
\hline
\end{tabular}

Kết quả bảng 3.7 cho thấy điểm kiến thức thấp nhất của người bệnh là 02 điểm, điểm cao nhất là 20 điểm. Điểm kiến thức trung bình của đối tượng là 12,5 trên tổng điểm 21. Có 69,7\% ĐTNC được hỏi có kiến thức về trầm cảm đạt từ mức trung bình trở lên. Vẫn còn $30,3 \%$ người bệnh có kiến thức về trầm cảm không đạt.

\section{BÀN LUẬN}

Trong tổng số 386 mẫu nghiên cứu được phỏng vấn, có 358 người chiếm $92,8 \%$ đã từng được nghe ít nhất 1 lần tới bệnh trầm cảm, 28 người còn lại chiếm $7,2 \%$ chưa từng nghe về bệnh trầm cảm. Tỷ lệ này cho thây với sự phát triển của khoa học công nghệ, các phương tiện truyền thông đã được phủ sóng rộng khắp trển cả nước, sự truyền dẫn thông tin tới người dân cũng đã đạt hiểu quả. Từ đó giúp người dân có được thông tin về bệnh. Trong số 92,8\% được nghe về bệnh trầm cảm thì nguồn thông tin chủ yếu là được cung cấp từ tivi, internet với $86,9 \%$. Với tỷ lệ này, ta thấy được rằng chúng ta cần nhắm tới kênh tuyên truyền nào để cung cấp một cách tối đa những thông tin cần thiết cho người bệnh, giúp họ có được kiến thức đúng, đủ để phòng tránh cũng như xử trí các tình huống có thể gặp phải. Chúng tôi không ghi nhận được 
kênh thông tin nào khác cung cấp thông tin đến người bệnh ngoài 3 kênh trên cho thấy, người bệnh đang điều trị $A R V$ nói riêng và người dân nói chung mới chỉ được tiếp cận thông tin từ những phương tiện thông tin đại chúng hay những truyền miệng từ người dân chứ chưa được cung cấp thông tin theo hình thức trực tiếp từ các nguồn tin chính thống như các buổi nói chuyện, tọa đàm hay những buổi truyền thông lưu động.

Trong nghiên cứu này, chúng tôi tìm thây có tới 29,5\% người bệnh không biết những biểu hiện trong giai đoạn đầu khi mới phát bệnh là gì và chỉ có $34(8,8 \%)$ người bệnh nhận biết được rằng tất cả 3 triệu chứng trên đều có thể là triệu chứng khởi phát của bệnh trầm cảm chứ không phải chỉ 1 hoặc 2 biểu hiện trong số đó. Với mức hiểu biết như vậy người bệnh và cả người thân của họ hoàn toàn có thể bỏ qua những triệu chứng của bệnh khi mà họ không nghĩ tới đó có thể là dấu hiệu của bệnh trầm cảm nên không đi khám hoặc không có sự quan tâm hơn đối với người thân của mình. Tỷ lệ người bệnh biết được cả 3 triệu chứng trong giai đoạn toàn phát là $17,1 \%$ cao hơn so với số người biết cả 3 triệu chứng của giai đoạn khởi phát là $8,8 \%$. Điều này cũng có thể giải thích do tình trạng bệnh nhân trầm cảm ở giai đoạn này đã biểu hiện rõ rệt có thể được người thân phát hiện và chẩn đoán bởi cán bộ y tế do đó người bệnh trong nghiên cứu của chúng tôi được tiếp xúc và nhận biết được bằng mắt thấy, tai nghe nên có kiến thức cụ thể hơn, nhớ rõ và lâu hơn nên những triệu chứng này được đối tượng nghiên cứu nhắc tới nhiều hơn.

Tổng hợp kết quả nghiên cứu kiến thức về nhận biết các biểu hiện của bệnh trầm cảm kể cả giai đoạn khởi phát và giai đoạn toàn phát chúng tôi ghi nhận được chỉ có 3,9\% đối tượng nghiên cứu biết được tất cả các biểu hiện của 2 giai đoạn trên, 36,5\% biết được từ 4 biểu hiện trong số 6 biểu hiện của cả 2 giai đoạn và có tới $26,2 \%$ biết tới bất kỳ biểu hiện nào. Điều này càng khẳng định rằng kiến thức của người dân đặc biệt là người nhiễm HIV đang điều trị ARV về bệnh trầm cảm còn rất thấp. Chưa tới $50 \%$ có kiến thức ở mức trung bình trở lên về biểu hiện của bệnh trâm cảm.

Về nguyên nhân của trầm cảm phần lớn người bệnh cho rằng 1 trong những nguyên nhân gây ra trầm cảm là do chấn thương tâm thần và cơ thể $(65,5 \%)$. Những chấn thương ở đây chúng ta có thể kể đến tang tóc, ly hôn, mất của, con cái tù tội, hư hỏng, về hưu. Sự căng thẳng quá độ đến từ những sự kiện, những biến động trong cuộc sống thường ngày, sự mất mát người thân, tranh cãi, áp lực trong công việc hay những mối quan hệ xấu với mọi người xung quanh gây ra những chấn thương về tâm thần của người bệnh, dần dần nếu không thể giải tỏa sẽ dẫn tới trầm cảm. Hoặc những gánh nặng về bệnh tật khiến người bệnh lo lắng, quan ngại về sức khỏe của mình. Đây cũng đúng là một trong số những phân loại nguyên nhân trầm cảm của các nhà tâm thần học đã công bố [5]. Đối với người Việt Nam, rất có thể người dân sẽ nghĩ tới những người bệnh trầm cảm thuộc nhóm nguyên nhân này có liển quan đến vấn đề tôn giáo, tâm linh do đặc thù phát triển về tôn giáo tại nước ta. Mặc dù chưa có giả thuyết nào được giải thích và chứng minh cho nhóm nguyên nhân này một cách rõ ràng nhưng nó vần là một yếu tố mà chúng ta cần lưu ý khi xác định tình trạng trầm cảm của bệnh nhân. Trong những nguyên nhân gây ra trầm cảm còn có nhóm nguyên nhân do người bệnh dùng thuốc có tác dụng phụ gây ra trầm cảm. Ví dụ như: Thuốc an thần kinh (Aminazin); thuốc gây nghiện (thuốc an thần, ma tuý...) [5]. Như phân tích yếu tố liên quan đến tình trạng trầm cảm của bệnh nhân HIV/AIDS chúng tôi cũng đã tìm thấy mối liên quan giữa việc sử dụng ma túy với tình trạng trầm cảm của người bệnh. Điều này cũng phù hợp với một trong những nhóm nguyên nhân trầm cảm trên.

Với câu hỏi về hậu quả mà trầm cảm gây ra đối với người bệnh, phần lớn đối tượng nghiên cứu đều biết đến hậu quả người bệnh trầm cảm có thể làm hại bản thân và người xung quanh và tự tử với tỷ lệ lần lượt được lựa chọn là $65,5 \%$ và $58,3 \%$. Chỉ có $8,8 \%$ số người được hỏi cho rằng người bệnh trâm cảm có thể bị tử vong do những bệnh cơ thể mà họ gặp phải. Có thể đối tượng nghiên cứu cho rằng những người bệnh trầm cảm ít có khả năng bị tử vong do bệnh khác vì họ chỉ mắc rối loạn về tâm thần. Tuy nhiên, một trong số những nguyên nhân gây ra trầm cảm đó là những chấn thương về cơ thể, cụ thể ở đây là những bệnh cơ thể, đặc biệt là những bệnh nan $y$, khó chữa trị hoăc thời gian điều trị lẩu dài hay những bệnh khiến họ có thể nhận phải sự kỳ thị của xã hội như HIV/AIDS.

Mặc dù tỷ lệ nhận biết các đặc điểm về bệnh trầm cảm còn thấp nhưng phần Iớn $(96,9 \%)$ vẫn trả lời rằng trầm cảm cần phải được điều trị để người bệnh trầm cảm có thể có cuộc sống bình thường, tốt đẹp như mọi người. Tuy nhiên, vẫn có $27,5 \%$ người bệnh không xác định được trầm cảm có thể được điều trị bằng phương pháp nào; 
55,4\% đã chọn được đáp án đúng nhất trong các phương pháp mà chúng tôi đưa ra đó là điều trị bằng uống thuốc, $30,6 \%$ cho rằng có thể điều trị trầm cảm bằng vật lý trị liệu, $1,6 \%$ cho rằng có thể phẫu thuật; 3 người $(0,5 \%)$ chọn điều trị bằng phương pháp khác là điêu trị tâm lý, đây cũng là phương pháp điều trị dành cho một vài thể của bệnh trầm cảm. Trên thực tế, có nhiều phương pháp điều trị trầm cảm tương ứng với mối thể bệnh. Trong nghiên cứu này chúng tôi chỉ đề cập đến một phương án đúng là uống thuốc.

Có $69,7 \%$ số đối tượng nghiên cứu có kiến thức về trầm cảm ở mức đạt (trả lời đúng $50 \%$ số đáp án đúng trở lên). Mặc dù có quá nửa số người bệnh được hỏi đạt được kết quả này nhưng đây cũng không phải là một tỷ lệ cao. Hơn nữa đây chỉ là những kiến thức hết sức ngắn gọn và cơ bản, dễ nhớ, dễ hiểu nhất về bệnh trầm cảm đối với người bệnh đang điều trị $A R V$ nên chúng tôi cho rằng đây là một kết quả chưa phải là tốt. Do đó cần có các biện pháp để cải thiện không chỉ kiến thức mà cả thái độ cũng như thực hành của người bệnh về trầm cảm.

\section{KẾT LUÂ̂N}

Tỷ lệ đối tượng nghiên cứu đã từng được nghe ít nhất 1 lần về bệnh trầm cảm chiếm tỷ lệ khá cao $(92,8 \%)$; Còn tỷ lệ thấp $(36,5 \%)$ số
ĐTNC biết được từ 4 biểu hiện trong số 6 biểu hiện của cả 2 giai đoạn khởi phát và toàn phát của bệnh; Chỉ có 31,6\% người bệnh kể được 2-3 trong số 3 nhóm nguyên nhân chính; Tỷ lệ đối tượng nghiên cứu có kiến thức đạt về trầm cảm chiếm tỷ lệ khá thấp $(69,7 \%)$

\section{KHUYẾN NGH!}

Tăng cường tuyên truyền, phổ biến kiến thức về phòng chống trầm cảm cho người bệnh điều trị $A R V$, nội dung tập trung ưu tiên về: nhóm nguyên nhẩn, cách phát hiện, giai đoạn phát của bệnh, cách phòng ngừa bệnh.

\section{TÀI LIÊU THAM KHẢO}

1. BMj Publishing Group (2018), Tổng quan về HIV, BMJ Best Practice.

2. Maria Giulia Nanni và các công sự (2015), "Depression in HIV infected patients: a review", Current psychiatry reports. 17(1), pp. 530.

3. Jacob K Saravanan B, Jonhson $S$, et al. (2007), "Belief models in first episode schizophrenia in South India", Social psychiatry and psychiatric epidemiology. 42(6), pp. 446-451.

4. Cohen N. L Srinivasan J, Parikh S. V. (2003) "Patient attitudes regarding causes of depression: implications for psychoeducation", Canadian Journal of Psychiatry. 48(7), pp. 493-495.

5. Nguyến Minh Tuấn (2002), Các rối loạn tâm thẩn chẩn đoán và điều trị, Nhà xuất bản $Y$ học, Hà Nội, tr.78-87.

\section{ĐÁNH GIÁ KẾT QUẢ ĐIỀU TRI PHÙ HOÀNG ĐIỂM DO ĐÁI THÁO ĐƯờNG BẰNG TIÊM RANIBIZUMAB NộI NHÃN}

\section{TÓM TẮT}

Mục tiêu: đánh giá kết quả điều trị phù hoàng điểm (HĐ) do đái tháo đường (DTÐ) bằng tiêm Ranibizumab nội nhãn tai Bệnh viện Mắt Hà Nội. Đối tượng và phương pháp nghiên cứu: 30 mắt của 30 bệnh nhân được chẩn đoán phù $\mathrm{HD}$ do ĐTÐ điêu trị bằng tiêm nội nhãn Ranibizumab taii Bệnh viện Mắt Hà Nội từ 10/2020 đến 5/2021. Nghiển cứu can thiệp lâm sàng không đối chứng. Kết quả: Hình thái phù trên OCT trước điều trị đước chia làm 3 nhóm: phù đơn thuần $13 / 30(43,3 \%)$, phù dạng nang $9 / 30$ $(33,0 \%)$, phù kèm bong thanh dịch võng mạc $8 / 30$

\footnotetext{
${ }^{1}$ Bệnh viện Mắt Hà nội,

2 Trường Đai hoc Y Hà Nôi

${ }^{3}$ Hội nhãn khoa Việt Nam

Chịu trách nhiệm chính: Nguyễn Thị Thanh

Email: nguyenthithanh81@yahoo.com

Ngày nhận bài: 13.9.2021

Ngày phản biên khoa học: 2.11.2021

Ngày duyệt bài: 15.11.2021
}

Nguyễn Thị Thanh ${ }^{1}$, Mai Quốc Tùng ${ }^{2}$, Hoàng Thị Phúc ${ }^{3}$ $(26,7 \%)$. 30/30 mắt đều cải thiên thị lực dần sau mỗi tháng điêu trị, 30/30 mắt có độ dày võng mạc trung tâm (CRT) giảm dần theo mỗi tháng điêu trị, sự khác biệt CRT trước và sau 3 tháng điêuu trị có ý nghĩa thổng kê với $p<0,001$. Kết luận: $30 / 30$ mắt đều cải thiện thị lực dân sau mối tháng điều trị, 30/30 mắt có độ dày võng mạc trung tâm (CRT) giảm dần theo mối tháng điêu trị, sự khác biệt CRT trước và sau 3 tháng điều trị có ý nghî̉a thống kề với $p<0,001$.

Từ khóa: phù hoàng điểm đái tháo đường, chiều dày võng mạc trung tâm

\section{SUMMARY \\ EVALUATION OF TREATMENT OUTCOMES \\ FOR INTRAVITREAL RANIBIZUMAB IN DIABETIC MACULAR EDEMA \\ Purpose: toevaluate the treatment outcomes of} intravitreal Ranibizumab injection for diabetic macular edema in $\mathrm{Ha}$ Noi Eye Hospital. Subjectives and Methods: 30 eyes of 30 patients treated with intravitreal Ranibizumab injection for diabetic macular edema included. Methods: prospectively 